Research Paper

\title{
Curcumin Sensitizes Silymarin to Exert Synergistic Anticancer Activity in Colon Cancer Cells
}

\author{
Amanda Montgomery ${ }^{1}$, Temitope Adeyeni2,3, KayKay San³, Rita M. Heuertz ${ }^{3}$ and Uthayashanker R. \\ Ezekiel $^{3 凶}$ \\ 1. Department of Nutrition and Dietetics, Saint Louis University St. Louis, MO 63104, USA; \\ 2. Department of Health Science and Informatics, Saint Louis University St. Louis, MO 63104, USA; \\ 3. Biomedical Laboratory Science, Saint Louis University St. Louis, MO 63104, USA. \\ $\triangle$ Corresponding author: Uthayashanker R. Ezekiel, PhD. Biomedical Laboratory Science, Saint Louis University St. Louis, MO 63104, USA; Phone. \\ 1(314)977-8689, Fax. 1(314)977-8503, e-mail.uezekiel@slu.edu. \\ () Ivyspring International Publisher. Reproduction is permitted for personal, noncommercial use, provided that the article is in whole, unmodified, and properly cited. See \\ http://ivyspring.com/terms for terms and conditions.
}

Received: 2016.03.29; Accepted: 2016.05.19; Published: 2016.06.23

\begin{abstract}
We studied combinatorial interactions of two phytochemicals, curcumin and silymarin, in their action against cancer cell proliferation. Curcumin is the major component of the spice turmeric. Silymarin is a bioactive component of milk thistle used as a protective supplement against liver disease. We studied antiproliferative effects of curcumin alone, silymarin alone and combinations of curcumin and silymarin using colon cancer cell lines (DLD-1, HCT116, LoVo). Curcumin inhibited colon cancer cell proliferation in a concentration-dependent manner, whereas silymarin showed significant inhibition only at the highest concentrations assessed. We found synergistic effects when colon cancer cells were treated with curcumin and silymarin together. The combination treatment led to inhibition of colon cancer cell proliferation and increased apoptosis compared to single compound treated cells. Combination treated cells exhibited marked cell rounding and membrane blebbing of apoptotic cells. Curcumin treated cells showed 3 -fold more caspase $3 / 7$ activity whereas combination treated cells showed 5 -fold more activity compared to control and silymarin treated cells. When DLD-1 cells were pre-exposed to curcumin, followed by treatment with silymarin, the cells underwent a high amount of cell death. The pre-exposure studies indicated curcumin sensitization of silymarin effect. Our results indicate that combinatorial treatments using phytochemicals are effective against colorectal cancer.
\end{abstract}

Key words: curcumin, silymarin, synergy, colon cancer, phytochemicals.

\section{Introduction}

The incidence rate of cancer and other chronic diseases have been associated with the lack of eating healthy foods, such as fruits and vegetables, and the consumption of western diets rich in processed foods and meat. Several scientific and epidemiological studies have shown strong associations between colon cancer and dietary factors. Colorectal cancer was the third most common cancer with nearly 1.4 million new cases in 2012 [1]. Though the colon cancer rate for Americans aged 50 and older is dropping due to effective screening, colon and rectal cancer rates are rising in younger Americans [2]. A recent study predicts that by 2030, the 20-34 age group will see colon cancer rates increase by $90 \%$ and rectal cancer rates increase by $124 \%$ [2]. Only 5 to $10 \%$ of colon cancers are due to genetic predisposition; others are due to diet and lifestyle habits [3]. Therefore changing diet and lifestyle habits has great potential to reduce incidence of colorectal cancer.

Fruits, vegetables, and spices contain a wide variety of phytochemicals that may offer protection against colon cancer. Occasional exposure of colon cells to a single phytochemical may be insignificant. However, combinations of phytochemicals may provide additive or synergistic effects, and have effectiveness at low doses making them potent ways 
to prevent or eliminate colon cancer initiation and/or progression. Many medicinal plants have been used with no side effects and phytochemicals derived from them exhibit anticancer properties [4]. Studies have shown that phytochemicals, such as curcumin, genistein, ellagic acid, silymarin and isothiocynates, exhibit readiosensitizing and chemosensitizing properties [4]. Current chemotherapeutic agents' exhibit high toxicities and side effects: phytochemicals derived from plants offer safety and no side effects. Also, a single phytochemical at high concentration may exhibit anticancer activity. By combining two phytochemicals, anticancer activity at much lower doses has been sought. Our present study is aimed at single versus combination phytochemical effects against colorectal cancer cells. The hypothesis of this study was that combinations of phytochemicals exert beneficial health effects beyond what is provided by single phytochemicals alone. Additive or synergistic effects exerted that are protective may compensate for low amounts of phytochemicals present in foods.

The best approach for phytochemical use is to understand the mechanism of action of plant-derived compounds and use these compounds in combination with each other or current therapeutic agents so that low dosage treatment exerts maximum treatment benefits. Using this strategy, we have identified that curcumin, the major component of turmeric, when used in combination with silymarin, the bioactive component of milk thistle, elicits a maximum effect on inhibition of colon cancer cell proliferation. Results of clinical trials show that curcumin is non-toxic and well-tolerated (in $12 \mathrm{~g}$ dosages) [5]. Silymarin is used for liver health in traditional medicine [6]. Both silymarin and curcumin have shown inhibitory effects against several types of cancer [6-8]. In colorectal cancer cells, silymarin exhibits anti-proliferative effect only at high concentrations [9]. We investigated the in vitro effect of curcumin and silymarin alone and in combination on human colorectal cancer cell lines (DLD-1, LoVo, HCT116). Our results show that a curcumin + silymarin combination leads to more cell death by apoptosis than a single compound treatment alone. Also, curcumin sensitizes the anti-proliferative effect of silymarin.

\section{Materials and Methods}

\section{Cell Lines and Reagents}

Human colon cancer cells (DLD-1, LoVo, HCT116) were obtained from the American Type Culture Collection (Manassas, VA) and cultured $\left(37^{\circ} \mathrm{C}, 5 \% \mathrm{CO}_{2}\right)$ in Dulbecco's modified Eagle's medium (DMEM) supplemented with $10 \%$ fetal bovine serum, penicillin/streptomycin, glutamine, sodium pyruvate, and HEPES buffer. DMEM and culture medium supplements were purchased from Hyclone (Logan, UT). Curcumin and silymarin (Sigma-Aldrich, Inc, St. Louis, MO) were prepared and stored in DMSO at $100 \mathrm{mM}$ stock solutions.

\section{Cell Propagation and Cell Proliferation Assay}

DLD-1 cells were propagated $\left(37^{\circ} \mathrm{C}, 5 \% \mathrm{CO}_{2}\right)$ until confluence was reached. Cells were treated with trypsin $(0.25 \%)$ to detach them from culture plates followed by addition of enriched DMEM to neutralize trypsin. Cells (5000 cells/100 $\mu$ l) were added to each well of 96-well microplates and incubated overnight to allow cells to attach. Cells were treated with curcumin alone, silymarin alone or curcumin + silymarin combination $(12.5 \mu \mathrm{M}$ curcumin held constant: silymarin at concentrations of 1.56, 3.125, $6.25,12.5,25,50,100 \mu \mathrm{M})$. Cell proliferation was assessed using a previously described crystal violet method [10, 11]. Briefly, all dilutions were made immediately before addition to cells, all treatments were performed in quadruplicate, and each experiment was performed at least three times independently. In addition to treatment wells, control wells were assessed which included cell blanks (media only), growth controls (untreated cells plus media), and vehicle controls (untreated cells plus media plus DMSO at the highest concentration assessed). At $48 \mathrm{~h}$, cells were fixed by addition of glutaraldehyde $(20 \mu \mathrm{L}, 11 \%$ glutaraldehyde, $15 \mathrm{~min}$ rotation, $300 \mathrm{rpm})$, washed with water, dried and stained $(0.1 \%$ crystal violet). Crystal violet that was not cell-bound was removed by washing (3 water washes) and then plates were dried. Cell-bound crystal violet was solubilized ( $10 \%$ acetic acid) and absorbance was determined in a microplate reader (562 nm).

\section{Synergy Determination}

Percent cell survival results were converted to Fraction Affected (FA). This conversion was made as follows. $\mathrm{FA}=0$ represents $100 \%$ viability; $\mathrm{FA}=1$ represents $0 \%$ viability. Curcumin + silymarin interactions were assessed by Combination Index (CI) analysis using the CompuSyn software program (ComboSyn, Inc, Paramus, NJ) that is based on the Chou-Talalay equation [12]. Interpretations of CI results follow. CI values $<1$ indicate synergism; $=1$ indicates additivity; $>1$ indicates antagonism.

\section{Live and Apoptotic Cell Assay}

DLD-1 cells were seeded in a 96-well plate at a density of 5000 cells/well. The next day media were replaced and treatments added: DMSO (vehicle control), curcumin $(12.5 \mu \mathrm{M})$, silymarin $(12.5 \mu \mathrm{M})$ or combination of curcumin $(12.5 \mu \mathrm{M})$ and silymarin 
$(12.5 \mu \mathrm{M})$. Plates were incubated $\left(37^{\circ} \mathrm{C}, 5 \% \mathrm{CO}_{2}, 48 \mathrm{~h}\right)$. Cell viability and apoptosis were measured using the ApoTox-Glo ${ }^{\mathrm{TM}}$ Triplex Assay (Promega, Madison, WI) that quantitated activity of caspases-3/7. The basis of the assay was that a fluorogenic cell-permeable peptide gets cleaved by a protease upon entry into living cells and cleaved peptides generated a fluorescent signal proportional to number of live cells. Fluorescence intensity was measured at the wavelengths $405_{\mathrm{EX}} / 505_{\mathrm{EM}}$. The next step was addition of Caspase-Glo 3/7 reagent (luminogenic substrate with tetrapeptide sequence DEVD attached) to microwells and incubation (room temperature). Caspase digestion of the peptide released a luciferase substrate and resulted in luciferase action (production of the luminescent signal). Fluorescence and luminescence were measured with a Synergy ${ }^{\circledR}$ instrumentation (Biotek, Winooski, VT).

\section{Western Blot}

After treatment of cells with vehicle or phytochemicals, cells were solubilized in lysis buffer (50 mM Tris, $100 \mathrm{mM} \mathrm{NaCl}, 2.5 \mathrm{mM}$ EDTA, 1\% Triton X-100, 1\% Nonidet P-40,2.5 mM Na $3 V_{4}, 25 \mu \mathrm{g} / \mathrm{ml}$ aprotinin, $25 \mu \mathrm{g} / \mathrm{ml}$ leupeptin, $25 \mu \mathrm{g} / \mathrm{ml}$ pepstatin $\mathrm{A}$, and $1 \mathrm{mM}$ phenylmethylsulfonyl fluoride) and centrifuged $(10,000 \mathrm{~g}, 15 \mathrm{~min})$. Supernatant was removed and protein concentration determined by the BCA method (Pierce Biotechnology, Rockford, IL). Cell lysates containing $20 \mu \mathrm{g}$ of protein were separated by SDS gel electrophoresis after which proteins were transferred electrophoretically onto a nitrocellulose membrane (Pierce Biotechnology, Rockford, IL). The membrane was blocked using blocking buffer (TBST: $20 \mathrm{mM}$ Tris, pH7.6, $100 \mu \mathrm{M}$ $\mathrm{NaCl}, 0.1 \%$ Tween-20, 5\% nonfat dry milk) and incubation ( $1 \mathrm{~h}$, room temperature, gentle agitation). After blocking, the membrane was washed and incubated with primary anti-caspase-3 antibody (Cell Signaling Technology, Danvers, MA) in TBST blocking buffer (overnight, $4^{\circ} \mathrm{C}$ ). Primary antibody was then removed, membrane washed three times with TBST and incubated with horseradish peroxidase-labeled secondary antibody $(1 \mathrm{~h}$, room temperature). Immunoreactive bands were visualized by a chemiluminescent detection system (Pierce Biotechnology, Rockford, IL). $\beta$-actin was used as the loading control.

\section{Sensitizing Effect of Phytochemical}

A pre-treatment experiment was performed to determine whether curcumin or silymarin mediated a sensitizing effect. Cells were pre-treated with either curcumin or silymarin for 24 hours. After pretreatment, the cells were washed with DMEM media without serum and treated with curcumin (if pretreated with silymarin) or silymarin (if pretreated with curcumin) with varying concentrations of the phytochemicals for $48 \mathrm{~h}$.

In an initial experiment of silymarin pre-exposure curcumin-treatment, cells were exposed $\left(24 \mathrm{~h}, 37^{\circ} \mathrm{C}\right)$ to silymarin at three different concentrations $(25,50,100 \mu \mathrm{M})$ or vehicle (DMSO), washed with DMEM media without serum and then incubated with curcumin $(3.125 \mu \mathrm{M})$. Besides DMSO vehicle control, another control was cells that were not pre-exposed to silymarin, that is, cells incubated only with curcumin $(3.125 \mu \mathrm{M})$ treatment. Results of silymarin pre-exposed, curcumin-treated cells were compared to results of no silymarin pre-exposure, curcumin treated cells.

The reverse experiment was also performed. For curcumin pre-exposure, silymarin-treatment studies, cells were exposed $\left(24 \mathrm{~h}, 37^{\circ} \mathrm{C}\right)$ to curcumin at three different concentrations $(3.125,6.25,12.5 \mu \mathrm{M})$ or vehicle (DMSO), washed with DMEM media without serum and then incubated with silymarin $(3.125 \mu \mathrm{M})$. Cells that were not pre-exposed to curcumin, that is, cells incubated only with silymarin $(3.125 \mu \mathrm{M})$ treatment served as no pre-exposure controls. Results of curcumin pre-exposed, silymarin-treated cells were compared to results of no curcumin pre-exposure, silymarin treated cells.

\section{Statistics}

Data were reported as mean \pm SEM. Comparisons of the compounds were performed utilizing ANOVA followed by post hoc Bonferroni pairwise comparisons. Significance was reported at $\mathrm{p}<0.05$ unless otherwise stated.

\section{Results}

\section{Antiproliferative Effects of Curcumin, Silymarin and Curcumin + Silymarin Combination}

Three colorectal cancer cell lines (DLD-1, LoVo, HCT116) were exposed to silymarin alone, curcumin alone, or curcumin and silymarin in combination (curcumin concentration constant $(12.5 \mu \mathrm{M})$ while varying silymarin concentration from 1.56 to $100 \mu \mathrm{M})$. Inhibitory concentrations $\left(\mathrm{IC}_{50}\right)$ for curcumin were determined in each cell line with results as follow: $12.0 \pm 0.9 \mu \mathrm{M}$ for DLD-1 cells; $12.6 \pm 2 \mu \mathrm{M}$ for LoVo cells; and $7 \pm 0.6 \mu \mathrm{M}$ for HCT116 cells. Curcumin $(12.5 \mu \mathrm{M})$ was selected for use as the concentration at which curcumin was held constant in combination studies. Similarly, $\mathrm{IC}_{50}$ for silymarin was assessed and determined to be $161 \pm 9 \mu \mathrm{M}$ for DLD-1 cells (data not shown) which justified performance of silymarin 
concentration response up to $100 \mu \mathrm{M}$ for single and combination compound treatment.

Results evident in all three cell lines were that silymarin alone showed significant inhibition of cell growth only at higher concentrations (Figure 1A-C) whereas curcumin alone exhibited a marked effect on all three cell lines, starting at $3.125 \mu \mathrm{M}$ for DLD-1 and HCT116 cells and $6.25 \mu \mathrm{M}$ for LoVo cells. (Figure 1A-C). To determine whether curcumin + silymarin combination treatments exhibited more antiproliferative effects than either compound alone, colorectal cancer cell lines (DLD-1, LoVo, HCT116) were treated with curcumin+silymarin combination, that is, curcumin held constant (at $12.5 \mu \mathrm{M}$ ) and varying silymarin concentrations $(1.56,3.125,6.25$, $12.5,25,50,100 \mu \mathrm{M})$. It was observed that no statistically significant difference existed between curcumin and silymarin alone treated cells at 1.56 and $3.125 \mu \mathrm{M}$ in DLD-1 and LoVo cells (Figure 1A and B), but a significant difference existed between combination treated and single compound-treated cells even at low dose (Figure 1A and 1B). At higher concentrations of curcumin alone and curcumin + silymarin compounds ( 25 to $100 \mu \mathrm{M})$, no statistically significant difference was observed, mainly because maximum cell death occurred at these concentrations (Figure 1A-C). Therefore, curcumin + silymarin compound inhibited significantly $(\mathrm{p}<0.001)$ more cell growth than silymarin alone at all concentrations tested (Figure 1A-C). Combination compound inhibited significantly $(\mathrm{p}<0.001)$ more cell growth than curcumin alone (at concentrations of 1.56, 3.125, $6.25 \mu \mathrm{M}$ : Figure 1A-C).

Combination index (CI) analysis was used to determine whether the effect was synergistic, additive or antagonistic using the CompuSyn system. Percent cell survival from DLD-1 data (Figure 1A) was converted to growth inhibition, termed Fraction Affected (FA), and plotted against the CI (Figure 1D). With the single exception of combination treatment with curcumin $(12.5 \mu \mathrm{M})$ and silymarin $(1.56 \mu \mathrm{M})$, all combination ratios exhibited $\mathrm{CI}<1$ which indicated a synergistic interaction between the two compounds [13].
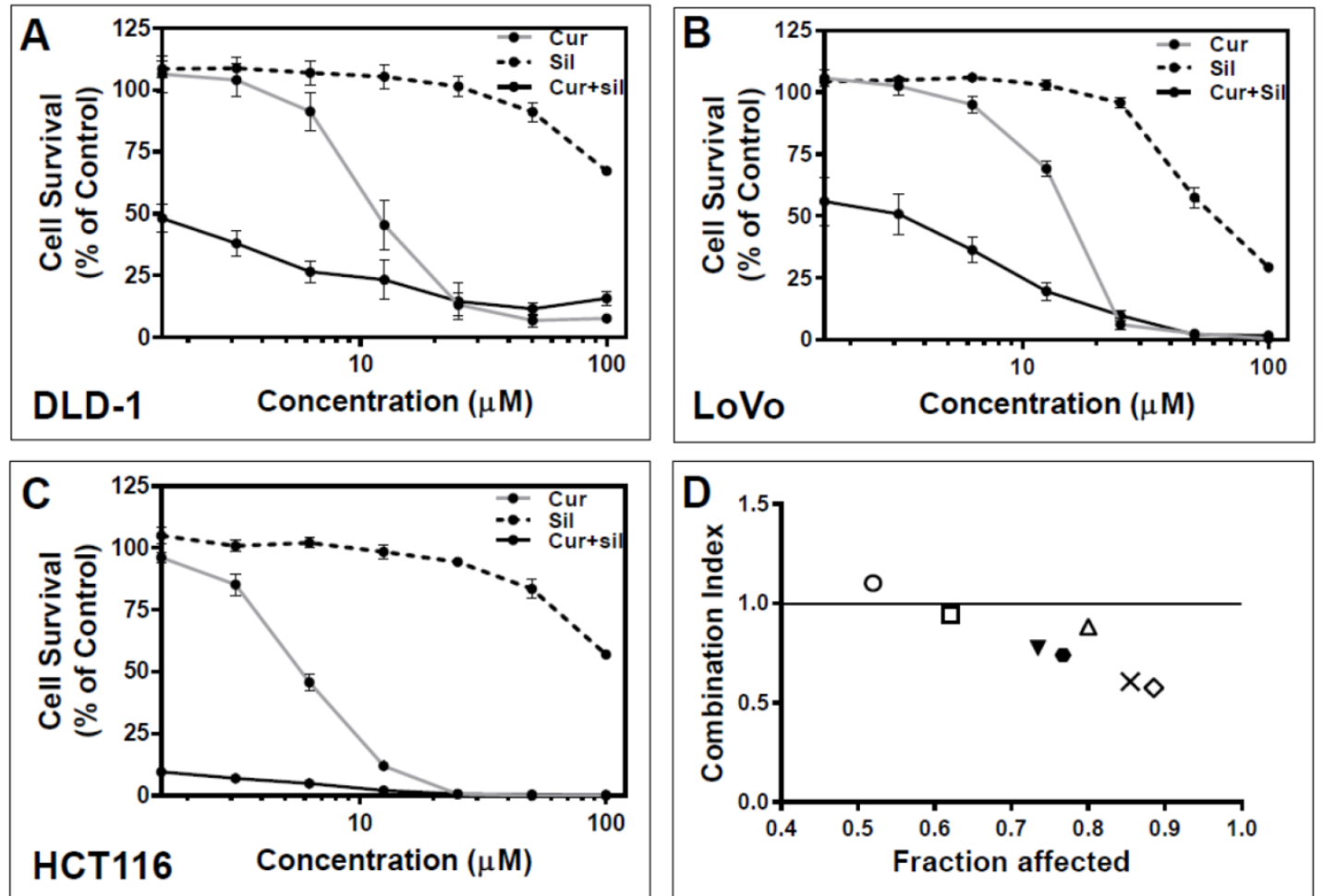

Figure 1. Antiproliferative effects of curcumin, silymarin and curcumin+silymarin combination on colon cancer cell viability. Phytochemicals (curcumin, silymarin) at different concentrations (1.56-100 $\mu \mathrm{M}$ ) were tested for anti-proliferative effects when presented to colon cancer cells (DLD-1, LoVo, HCT116) singly or in combination (i.e., $12.5 \mu \mathrm{M}$ curcumin held constant and silymarin at varying concentrations). (A). DLD-1 colon cancer cell results. (B). LoVo colon cancer cell results. (C). HCT116 colon cancer cell results. In all cell lines tested, combination compound treatments showed significant differences compared to single compound treatments ( $<0.01$ at

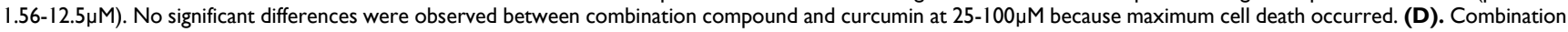
Index $(\mathrm{Cl})$ analysis of growth inhibition in DLD-1 cells after $48 \mathrm{~h}$ incubation using curcumin $(12.5 \mu \mathrm{M})$ and silymarin (varying concentrations). Data from Figure $1 \mathrm{~A}$ were converted to Fraction Affected (FA) and plotted against Combination Index ( $\mathrm{Cl}$ ). Combination treatments were curcumin (held constant at $12.5 \mu \mathrm{M}$ ) and silymarin (at varying concentrations). Results were as follows for silymarin concentration: $O=1.56 \mu \mathrm{M} ; \square=3.125 \mu \mathrm{M} ; \boldsymbol{\nabla}=6.25 \mu \mathrm{M} ; \bullet=12.5 \mu \mathrm{M} ; \Delta=25 \mu \mathrm{M} ; \mathrm{X}=50 \mu \mathrm{M}$; and $\diamond=100 \mu \mathrm{M}$. Straight line on the graph designates a $\mathrm{Cl}$ equal to 1 . Combination Index interpretation was as follows: $\mathrm{Cl}$ value of 1 indicates additivity; $\mathrm{Cl}<1$ indicates synergism; and $\mathrm{Cl}>1$ indicates antagonism. 

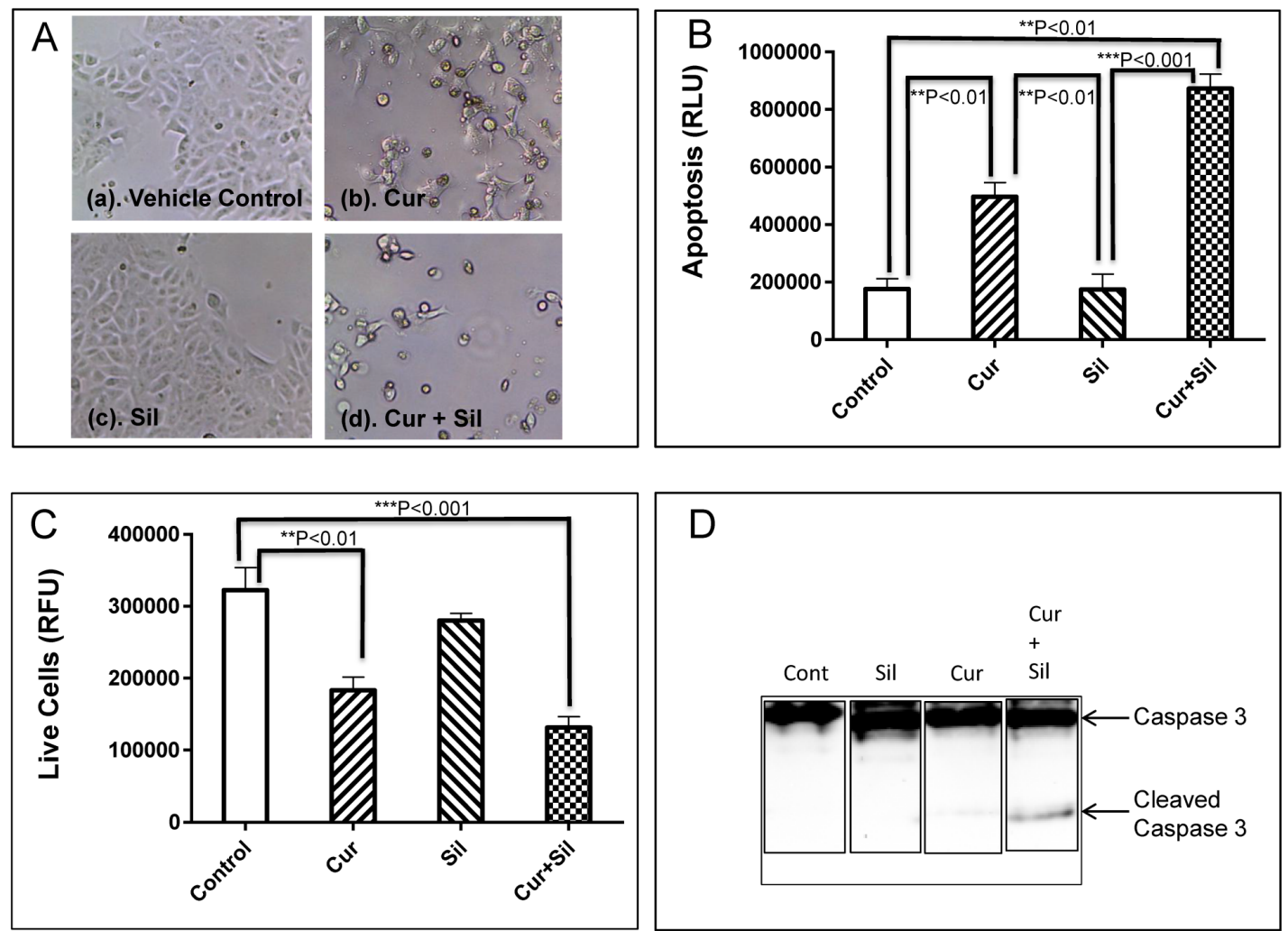

Figure 2. Increased apoptosis was induced by curcumin + silymarin combination treatment of DLD-1 colon cancer cells. (A). Phase contrast microscopic images (10X objective) of DLD-1 colon cancer cells after $48 \mathrm{~h}$ of treatment with (a) DMSO vehicle control; (b) curcumin alone at $12.5 \mu \mathrm{M}$ CUR; (c) silymarin alone at $12.5 \mu \mathrm{M}$ Sil; and (d) combination of curcumin+silymarin (12.5 $\mu \mathrm{M}$ for each compound). Morphological appearance of blebbing and cell shrinkage was visible in cells treated with curcumin alone (b) and curcumin + silymarin combination (d) indicating apoptosis. No morphological appearance of apoptotic cells was present in control (a) and silymarin- treated cells (c). (B). A caspase assay was used to identify apoptotic cells after $48 \mathrm{~h}$ treatment with phytochemicals. Except for control (vehicle) versus $12.5 \mu \mathrm{M}$ silymarin alone (Sil), significant differences were noted in all comparisons: control versus Cur alone at $12.5 \mu \mathrm{M}(\mathrm{p}<0.01)$; control versus combination treatment Cur+Sil ( $<0.01)$; Sil alone at $12.5 \mu \mathrm{M}$ versus Cur alone at $12.5 \mu \mathrm{M}(\mathrm{p}<0.01)$; and Sil alone at $12.5 \mu \mathrm{M}$ versus combination treatment Cur+Sil $(p<0.001)$. Data represented results of 3 independent experiments $(n=3)$. (C). DLD-1 live cells after $48 \mathrm{~h}$ treatment. There was a statistically significant reduction in live cells in curcumin alone Cur $12.5 \mu \mathrm{M}$ versus control ( $\mathrm{p}<0.01$ ); and combination Cur+Sil versus control cells $(\mathrm{p}<0.001)$. No statistically significant difference existed between control versus silymarin alone at $12.5 \mu M$. (D). Western blot analysis of treated cells for proteolytically cleaved, active caspase 3. Combination-treated cells (Cur+Sil each at $12.5 \mu \mathrm{M}$ ) exhibited a predominant band of cleaved caspase 3 : a lighter cleaved caspase-3 band was observed in the curcumin-treated cells (Cur at $12.5 \mu \mathrm{M})$. No active caspase-3 was detected in control or silymarin-treated cells. CUR $=$ curcumin. Sil $=$ silymarin.

\section{Increased Apoptosis Induced by Curcumin + Silymarin Combination Treatment}

DLD-1 cells were treated with curcumin or silymarin, alone or in combination, and morphological changes were observed after $48 \mathrm{~h}$ (Figure 2A). Cells treated with curcumin at $12.5 \mu \mathrm{M}$ (Figure 2A, panel b) and curcumin + silymarin combination (each at $12.5 \mu \mathrm{M}$ ) (Figure 2A, panel d) showed marked cell rounding and membrane blebbing suggestive of apoptosis compared to DMSO vehicle control (Figure 2A, panel a) and silymarin (Figure 2A, panel c) treated cells. Besides morphology as an indicator of apoptosis (Figure 2A), direct measures of apoptosis and live cells were obtained using an assay that measured inactive caspase (proenzyme) cleavage to the active form. The assay used was ApoTox-Glo ${ }^{\mathrm{TM}}$ from Promega that measured live and apoptotic cells by activities of caspases 3 and 7 and reported results as relative luminescence (RLU).
DLD-1 cells were treated with curcumin (12.5 $\mu \mathrm{M})$ alone, silymarin $(12.5 \mu \mathrm{M})$ alone or curcumin + silymarin combination (each at $12.5 \mu \mathrm{M}$ ) for $48 \mathrm{~h}$ and analyzed for caspase3/7 activity. Low levels of activity were observed for control (DMSO vehicle) and silymarin $(12.5 \mu \mathrm{M}$ Sil) and no statistically significant difference was observed between the two (Figure 2B). Increased caspase $3 / 7$ activity was evident in curcumin (12.5 $\mu \mathrm{M}$ Cur) and combination $(12.5 \mu \mathrm{M}$ Cur $+12.5 \mu \mathrm{M}$ Sil) compared to vehicle (control) and silymarin $(12.5 \mu \mathrm{M}$ Sil) treated cells (Figure 2B). Curcumin $(12.5 \mu \mathrm{M})$-treated cells showed 3 -fold more apoptosis than the control and combination-treated cells had 5-fold more apoptosis than control (Figure 2B). As expected, treated cells that exhibited high levels of apoptosis (that is, Cur $12.5 \mu \mathrm{M}$ alone and Cur $12.5 \mu \mathrm{M}+$ Sil $12.5 \mu \mathrm{M}$ combination) displayed significantly $(\mathrm{p}<0.01$ and $\mathrm{p}<0.001$ respectively) lower numbers of live cells than the control (Figure 2C). There was no significant difference in live cells between control-treated and silymarin alone-treated cells (Figure 2C). 

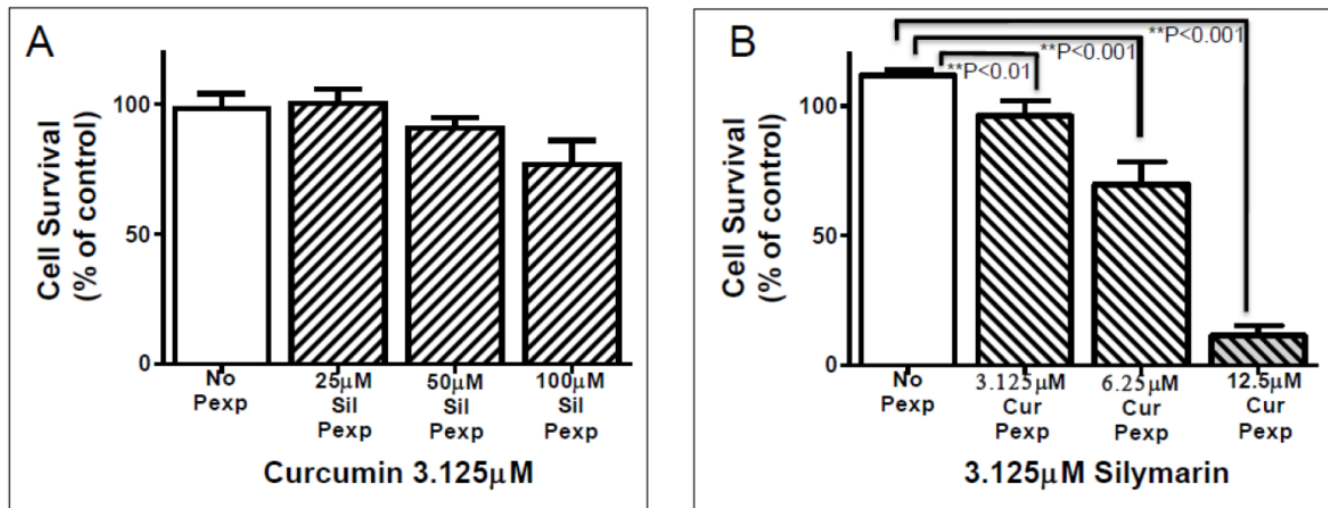

Figure 3. Phytochemical pre-treatment to assess sensitization effect. (A). DLD-1 cells were pre-exposed (Pexp: $24 \mathrm{~h})$ to silymarin at three different concentrations $(25,50,100 \mu \mathrm{M})$. Cells were then washed and treated with curcumin $(3.125 \mu \mathrm{M})$. No statistically significant difference existed between silymarin pre-exposed cells and those treated with curcumin. (B). DLD-1 cells were pre-exposed (Pexp: $24 \mathrm{~h}$ ) to curcumin at three different concentrations $(3.125,6.25,12.5 \mu \mathrm{M})$. Cells were then washed and treated with silymarin $(3.125 \mu \mathrm{M})$. Curcumin pre-exposed cells were all different in a statistically significant manner from the no pre-exposure cells (No Pexp): Cur Pexp ( $3.125 \mu \mathrm{M})$ versus No Pexp ( $p<0.01)$; Cur Pexp $(6.25 \mu \mathrm{M})$ versus No Pexp $(p<0.001)$; and Cur Pexp $(12.5 \mu M)$ versus No Pexp $(p<0.001)$.

To verify that active (cleaved) caspase 3 levels were indeed increased in the curcumin alone and curcumin + silymarin combination compared to silymarin alone and vehicle results, Western blot was performed (Figure 2D). Bands of uncleaved caspase 3 were evident in each lane of the blot; however, cleaved caspase 3 bands were evident only in curcumin alone (faint band) and combination (more intense band) lanes and absent in control and silymarin lanes (Figure 2D). Therefore, results suggested that combination treatment of cells exhibited increased apoptosis.

\section{Sensitization Effect of Curcumin on Silymarin}

Next, we performed a pre-exposure study to elucidate whether curcumin or silymarin mediated sensitization that led to synergistic effect in the combination group. DLD-1 cells were pre-exposed (24 h) to silymarin at three different concentrations (25, $50,100 \mu \mathrm{M})$. Cells were washed with serum-deficient medium and incubated $(48 \mathrm{~h})$ with curcumin $(3.125$ $\mu \mathrm{M})$. Percent cell survival was calculated based on no pre-exposure vehicle control (Figure 3A). Percent survival of silymarin pre-exposed $(25,50,100 \mu \mathrm{M})$ curcumin-treated $(3.125 \mu \mathrm{M})$ cells was compared to no pre-exposed, curcumin-treated cells (Figure 3A). No statistically significant difference was evident for the silymarin pre-exposed curcumin-treated cells versus no pre-exposed curcumin-treated cells (Figure 3A).

We performed the converse experiment in which DLD-1 cells were pre-exposed to curcumin (3.125, $6.25,12.5 \mu \mathrm{M})$ and treated with silymarin $(3.125 \mu \mathrm{M}$. Figure 3B). Curcumin pre-exposed silymarin-treated cells exhibited statistically significant differences when compared with no pre-exposure, silymarin-treated cells at each of the three curcumin concentrations tested (Cur $3.125 \mu \mathrm{M}$ was $\mathrm{p}<0.01$. CUR $6.25 \mu \mathrm{M}$ was $\mathrm{p}<0.001$. CUR $12.5 \mu \mathrm{M}$ was $\mathrm{p}<0.001$ )
(Figure 3B). Therefore, curcumin pre-exposure followed by silymarin treatment inhibited cell proliferation significantly compared to no curcumin pre-exposure control; whereas silymarin pre-exposure followed by curcumin treatment failed to inhibit cell proliferation compared to no silymarin pre-exposure (Figure 3 A, B). Pre-exposure to curcumin at all concentrations followed by treatment with silymarin $(3.125 \mu \mathrm{M})$ showed statistically significant differences compared to non-pre-exposure controls (Figure 3B). These results strongly suggest that curcumin sensitizes anti-proliferative effect of silymarin.

\section{Discussion}

We found that silymarin and curcumin inhibited proliferation of three colon cancer cell lines, DLD-1, LoVo, and HCT116 (Figure 1 A-C). Combination effects of silymarin and curcumin resulted in higher levels of inhibition of cancer cell growth than either silymarin or curcumin alone (Figure $1 \mathrm{~A}-\mathrm{C}$ ). Indeed, a synergistic effect on inhibition of DLD-1 cell proliferation was evident when curcumin and silymarin in combination were presented to the cells (Figure 1D). Combination Index analysis was assessed using a nonconstant ratio of curcumin and silymarin (Figure 1D). The Combination Index result of $<1$ indicated that the interaction was a synergistic one (Figure 1D). All Combination Index results showed synergism except one condition (curcumin at $12.5 \mu \mathrm{M}$ + silymarin at $1.56 \mu \mathrm{M})$ which exhibited a slight antagonistic interaction (Figure 1D).

The combination of both compounds showed a significant increase in apoptosis as analyzed by caspase $3 / 7$ activity assay (Figure 2B). Also, the increased cleaved caspase 3 protein was observed in Western blot only in combination treated cells (Figure 2D). To understand the synergistic interaction of both compounds, we performed pre-exposure 
experiments. The DLD-1 cells were pre-exposed to curcumin $(3.125,6.25,12.5 \mu \mathrm{M}$. $24 \mathrm{~h})$. At the $24 \mathrm{~h}$ time point, curcumin was removed by washes and then the cells were treated with silymarin $(3.125 \mu \mathrm{M})$. Percent cell survival was calculated compared to control. Results of no pre-exposure compared to curcumin pre-exposed, silymarin $(3.125 \mu \mathrm{M})$-treated cells caused a statistically significant pre-exposure dose-dependent decrease in cell survival compared to no pre-exposed cell control (Figure 3B). When comparing these curcumin pre-exposure results with silymarin pre-exposure results obtained in the converse experiment, no significant difference was observed between the no pre-exposure control and the silymarin pre-exposed, curcumin-treated cells (Figure 3A). Therefore, the data strongly suggests that curcumin sensitizes DLD-1 cells for silymarin-induced inhibitory effect thereby leading to an augmented effect on inhibition of cell proliferation. When cells were simultaneously exposed to both compounds, the curcumin-sensitizing effect augmented silymarin effect thereby providing evidence for the synergistic interaction.

Both curcumin, the curcuminoid present in turmeric, and silymarin from milk thistle [6] have reported anticancer properties in vitro and in vivo [5, $7,8]$. Several studies demonstrated that curcumin inhibited proliferation and induced apoptosis in several types of cancer [14-16]. Curcumin has also been credited with mediating radiosensitization and chemosensitization in cancer cells $[17,18]$. Curcumin, when combined with different phytochemicals, exhibited antiproliferative and cytotoxic effects against cancer in a synergistic manner [19-21]. For example, curcumin displayed synergistic anticancer activity when combined with epigallocatechenin-3gallate in human breast cancer [22], phenyl isothiocyanate in human prostate cancer cells [23, 24] and carnosic acid in human acute myeloid leukemia [20]. In the present study, we found that curcumin exhibited anticancer activity when combined with silymarin in a synergistic manner in the DLD-1 colon cancer cell line.

Phytochemicals showing synergistic activity may be more advantageous than traditional chemotherapy. Even though chemotherapy eliminates tumor cells, it leads to several side effects. In addition, both chemo- and radio-therapy have been shown to cause epithelial-mesenchymal transition (EMT) that subsequently resulted in metastasis of the tumor [25, 26]. Phytochemicals offer alternate therapeutic approaches to cancer treatments and avoid toxic states and side effects manifested by chemotherapeutic agents.
The anticancer activity of curcumin and silymarin have been shown to act on several cellular targets [27, 28]. It has been reported that NF-kB transcriptionally regulates various proteins that participate in prosurvival signaling, such as BCL2 and cyclin D [29-31], thereby implicating the NF-kB pathway as an active and significant player in cancer development [30, 32, 33]. Both curcumin and silymarin have been reported to inhibit NF-kB activity by suppressing protein phosphorylation [34, 35]. Cellular commitment to apoptosis depends upon a balance between proteins that mediate cell survival versus those that mediate cell death [36, 37]. Both curcumin and silymarin have been shown to modulate the balance between pro-apototic and anti-apoptotic proteins that leads to apoptosis of cancer cells (36-38). We hypothesize that the synergistic curcumin plus silymarin combination effect on DLD-1 cells is due to the ability of both compounds to suppress NF-kB activity. Future studies will explore the NF-kB and apoptotic pathways to understand synergisitic effects of curcumin and silymarin on colon cancer cells.

\section{Acknowledgments}

AM, TAA and KS were supported by the DeNardo Education and Research Foundation grant. Financial support for UE was provided by the President Research Fund from Saint Louis University. The authors wish to thank Dr. Patrick Kelly for his critical reading of the manuscript.

\section{Competing Interests}

The authors have declared that no competing interest exists.

\section{References}

1. Ferlay J, Soerjomataram I, Dikshit R, Eser S, Mathers C, Rebelo M, et al. Cancer incidence and mortality worldwide: sources, methods and major patterns in GLOBOCAN 2012. Int J Cancer. 2015; 136: E359-86.

2. Bailey CE, Hu CY, You YN, Bednarski BK, Rodriguez-Bigas MA, Skibber JM, et al. Increasing disparities in the age-related incidences of colon and rectal cancers in the United States, 1975-2010. JAMA surgery. 2015; 150: 17-22.

3. Jasperson KW, Tuohy TM, Neklason DW, Burt RW. Hereditary and familial colon cancer. Gastroenterology. 2010; 138: 2044-58.

4. Prasad NR, Muthusamy G, Shanmugam M, Ambudkar SV. South Asian Medicinal Compounds as Modulators of Resistance to Chemotherapy and Radiotherapy. Cancers (Basel). 2016; 8 .

5. Carroll RE, Benya RV, Turgeon DK, Vareed S, Neuman M, Rodriguez L, et al. Phase IIa clinical trial of curcumin for the prevention of colorectal neoplasia. Cancer prevention research. 2011; 4: 354-64.

6. Agarwal R, Agarwal C, Ichikawa H, Singh RP, Aggarwal BB. Anticancer potential of silymarin: from bench to bed side. Anticancer Res. 2006; 26: 4457-98.

7. Ramasamy K, Agarwal R. Multitargeted therapy of cancer by silymarin. Cancer Lett. 2008; 269: 352-62.

8. Shehzad A, Wahid F, Lee YS. Curcumin in cancer chemoprevention: molecular targets, pharmacokinetics, bioavailability, and clinical trials. Arch Pharm (Weinheim). 2010; 343: 489-99.

9. Hogan FS, Krishnegowda NK, Mikhailova M, Kahlenberg MS. Flavonoid, silibinin, inhibits proliferation and promotes cell-cycle arrest of human colon cancer. J Surg Res. 2007; 143: 58-65.

10. Duessel S, Heuertz RM, Ezekiel UR. Growth inhibition of human colon cancer cells by plant compounds. Clin Lab Sci. 2008; 21: 151-7. 
11. Basile V, Belluti S, Ferrari E, Gozzoli C, Ganassi S, Quaglino D, et al. bis-Dehydroxy-Curcumin triggers mitochondrial-associated cell death in human colon cancer cells through ER-stress induced autophagy. PLoS One. 2013; 8: e53664.

12. Chou TC, Talalay P. Quantitative analysis of dose-effect relationships: the combined effects of multiple drugs or enzyme inhibitors. Adv Enzyme Regul. 1984; 22: 27-55.

13. Chang TT, Chou TC. Rational approach to the clinical protocol design for drug combinations: a review. Acta Paediatr Taiwan. 2000; 41: 294-302.

14. Anand $\mathrm{P}$, Sundaram $\mathrm{C}$, Jhurani S, Kunnumakkara AB, Aggarwal BB. Curcumin and cancer: an "old-age" disease with an "age-old" solution. Cancer letters. 2008; 267: 133-64.

15. Hasima N, Aggarwal BB. Cancer-linked targets modulated by curcumin. IntJBiochemMolBiol. 2012; 3: 328-51.

16. Zhang JY, Lin MT, Zhou MJ, Yi T, Tang YN, Tang SL, et al. Combinational Treatment of Curcumin and Quercetin against Gastric Cancer MGC-803 Cells in Vitro. Molecules. 2015; 20: 11524-34.

17. Goncalves Vde P, Ortega AA, Guimaraes MR, Curylofo FA, Rossa Junior C, Ribeiro DA, et al. Chemopreventive activity of systemically administered curcumin on oral cancer in the 4-nitroquinoline 1-oxide model. Journal of cellular biochemistry. 2015; 116: 787-96

18. Shehzad A, Park JW, Lee J, Lee YS. Curcumin induces radiosensitivity of in vitro and in vivo cancer models by modulating pre-mRNA processing factor 4 (Prp4). Chem Biol Interact. 2013; 206: 394-402.

19. Guo J, Li W, Shi H, Xie X, Li L, Tang H, et al. Synergistic effects of curcumin with emodin against the proliferation and invasion of breast cancer cells through upregulation of miR-34a. Mol Cell Biochem. 2013; 382: 103-11.

20. Pesakhov S, Khanin M, Studzinski GP, Danilenko M. Distinct combinatorial effects of the plant polyphenols curcumin, carnosic acid, and silibinin on proliferation and apoptosis in acute myeloid leukemia cells. Nutrition and cancer. 2010; 62: 811-24.

21. Parasramka MA, Gupta SV. Synergistic effect of garcinol and curcumin on antiproliferative and apoptotic activity in pancreatic cancer cells. JOncol. 2012; 2012: 709739 .

22. Somers-Edgar TJ, Scandlyn MJ, Stuart EC, Le Nedelec MJ, Valentine SP, Rosengren RJ. The combination of epigallocatechin gallate and curcumin suppresses ER alpha-breast cancer cell growth in vitro and in vivo. Int J Cancer. 2008; 122: 1966-71.

23. Khor TO, Keum YS, Lin W, Kim JH, Hu R, Shen G, et al. Combined inhibitory effects of curcumin and phenethyl isothiocyanate on the growth of human PC-3 prostate xenografts in immunodeficient mice. Cancer research. 2006; 66: 613-21.

24. Cheung KL, Khor TO, Kong AN. Synergistic effect of combination of phenethyl isothiocyanate and sulforaphane or curcumin and sulforaphane in the inhibition of inflammation. Pharmaceutical research. 2009; 26: 224-31.

25. Yang AD, Fan F, Camp ER, van Buren G, Liu W, Somcio R, et al. Chronic oxaliplatin resistance induces epithelial-to-mesenchymal transition in colorectal cancer cell lines. Clinical cancer research : an official journal of the American Association for Cancer Research. 2006; 12: 4147-53.

26. Kawamoto A, Yokoe T, Tanaka K, Saigusa S, Toiyama Y, Yasuda H, et al. Radiation induces epithelial-mesenchymal transition in colorectal cancer cells. Oncology reports. 2012; 27: 51-7.

27. Deguchi A. Curcumin targets in inflammation and cancer. Endocr Metab Immune Disord Drug Targets. 2015.

28. Gupta SC, Sung B, Kim JH, Prasad S, Li S, Aggarwal BB. Multitargeting by turmeric, the golden spice: From kitchen to clinic. MolNutrFood Res. 2012.

29. Li L, Aggarwal BB, Shishodia S, Abbruzzese J, Kurzrock R. Nuclear factor-kappaB and IkappaB kinase are constitutively active in human pancreatic cells, and their down-regulation by curcumin (diferuloylmethane) is associated with the suppression of proliferation and the induction of apoptosis. Cancer. 2004; 101: 2351-62.

30. Gambhir S, Vyas D, Hollis M, Aekka A, Vyas A. Nuclear factor kappa B role in inflammation associated gastrointestinal malignancies. World J Gastroenterol. 2015; 21: 3174-83.

31. Munoz A, Costa M. Nutritionally mediated oxidative stress and inflammation. Oxidative medicine and cellular longevity. 2013; 2013: 610950.

32. Tong L, Yuan Y, Wu S. Therapeutic microRNAs targeting the NF-kappa B signaling circuits of cancers. Adv Drug Deliv Rev. 2015; 81: 1-15.

33. Li F, Zhang J, Arfuso F, Chinnathambi A, Zayed ME, Alharbi SA, et al. NF-kappaB in cancer therapy. Arch Toxicol. 2015; 89: 711-31.

34. Gao X, Wang B, Wu Q, Wei X, Zheng F, Men K, et al. Combined Delivery and Anti-Cancer Activity of Paclitaxel and Curcumin Using Polymeric Micelles. J Biomed Nanotechnol. 2015; 11: 578-89.

35. Miroliaee AE, Esmaily H, Vaziri-Bami A, Baeeri M, Shahverdi AR, Abdollahi M. Amelioration of experimental colitis by a novel nanoselenium-silymarin mixture. Toxicol Mech Methods. 2011; 21: 200-8.

36. Manna SK, Mukhopadhyay A, Van NT, Aggarwal BB. Silymarin suppresses TNF-induced activation of NF-kappa B, c-Jun N-terminal kinase, and apoptosis. JImmunol. 1999; 163: 6800-9.

37. Shehzad A, Lee J, Huh TL, Lee YS. Curcumin induces apoptosis in human colorectal carcinoma (HCT-15) cells by regulating expression of Prp4 and p53. Mol Cells. 2013; 35: 526-32.

38. Bandugula VR, Prasad NR. 2-Deoxy-D-glucose and ferulic acid modulates radiation response signaling in non-small cell lung cancer cells. Tumour Biol. 2013 34(1):251-9. 